\title{
The Effect of Rolling Temperature on the Microstructure and Mechanical Properties of Surface-Densified Powder Metallurgy Fe-Based Gears Prepared by the Surface Rolling Process
}

\author{
Di Chen ${ }^{1}$, Dekai Li ${ }^{1}$, Jingguang Peng ${ }^{1,2, *}$, Taolei Wang ${ }^{2}$, Biao Yan ${ }^{2}$ and Wei Lu ${ }^{2, *}$ \\ 1 Shanghai Automotive Powder Metallurgy Co. Ltd., Shanghai 201908, China; chendi1201@126.com (D.C.); \\ lidekaimilan@163.com (D.L.) \\ 2 Shanghai Key Lab of Research \& Development for Metal Functional Materials, School of Materials Science \\ and Engineering, Tongji University, Shanghai 201804, China; 1710045@tongji.edu.cn (T.W.); \\ yan_biao@tongji.edu.cn (B.Y.) \\ * Correspondence: jingguangp@shautopm.com.cn (J.P.); weilu@tongji.edu.cn (W.L.); \\ Tel.: +86-021-5605-3288 (J.P.); +86-021-6958-1508 (W.L.); Fax: +86-021-5695-4785 (J.P.); +86-021-6958-5265 (W.L.)
}

Received: 7 August 2017; Accepted: 25 September 2017; Published: 10 October 2017

\begin{abstract}
In this investigation, the surface-rolling process was performed to improve the performance of PM (powder metallurgy) parts. Different rolling temperatures were applied and the effect of rolling temperature on the microstructure and mechanical properties of the surface dense layers in the samples were investigated. In the study, room temperature and temperatures of $100{ }^{\circ} \mathrm{C}, 200^{\circ} \mathrm{C}$, $300{ }^{\circ} \mathrm{C}$ were studied during the rolling process. The results confirmed that the sample prepared with a pre-heated temperature of $200{ }^{\circ} \mathrm{C}$ had the lowest porosity at the surface area. It also exhibited the highest surface hardness and wear resistance. The optimum rolling temperature was determined to be $200{ }^{\circ} \mathrm{C}$ and the related mechanism was discussed.
\end{abstract}

Keywords: powder metallurgy; rolling densification; warm rolling; warm deformation

\section{Introduction}

Powder metallurgy technologies are especially suitable for net-shape forming of complex-shaped parts such as gears. Surface rolling densification technology has attracted much attention as an important process to improve the performance of parts. It allows for the cost-effective, high-precision processing of powder metallurgy (PM) gears with full surface density to improve the load bearing capacity. It exerts a certain pressure on the surface of the workpiece with the rolling tool and induces plastic deformation on the surface layer [1-3]. The shape and size of PM parts can be altered and the physical and mechanical properties of PM parts can also be improved. Therefore, this process can achieve the expected shape and improved properties at the same time $[4,5]$.

The cold rolling process has been proved to improve the surface density, surface roughness, abrasion resistance, and other properties of the surface layer. The warm rolling process is based on the ordinary cold rolling surface densification process, but has an extra heating process. Based on cold rolling technology, warm rolling is likely to further improve performance with the plastic deformation of the parts. When the warm rolling process is conducted, the parts are deformed under a certain temperature range, which is usually higher than the recovery temperature but lower than the recrystallization starting temperature [6]. During the process of warm deformation, work hardening will take place in the samples, accompanied by dynamic recovery softening and static softening within the gap moment of the deformation, although the work hardening effect is dominant [7]. The hardness and yield strength of the metals are dependent on the degree of work hardening and softening [8]. 
Compared with cold deformation, during the warm deformation process, metals have relative low yield strength, high plasticity, and low deformation resistance [9].

The PM gears achieved by selected surface densification have been applied in the automotive industry. Gunter et al. [10,11] proposed a densification strategy to achieve PM gears with high load-carrying capacity; Takemasu et al. [12,13] studied high-performance PM gears. Jones et al. [14] and Koide et al. [15] studied high-performance, surface-densified PM gears. Those studies indicated that a densification depth of $0.2-1 \mathrm{~mm}$ was formed on the surface layer with an obvious increase in density and surface hardness. The fatigue and wear resistance of the PM gears treated by surface densification can also be enhanced $[16,17]$. These reports emphasize the increased performance after rolling, although few address the warm rolling surface densification process on PM materials.

Previously, it was reported that the sub-crystal structure generated in the "blue-brittle" region and the phase transition zone was finer, which indicated that the warming process was beneficial to the strengthening of the samples [18]. Moderate temperature deformation can achieve a denser deformation than cold deformation, and promote the dispersion of carbide precipitation, thus improving the strength and toughness of the material [19]. Richards found that an axle treated with warm rolling has a longer fatigue life than that treated with cold rolling, indicating the advantage of the warm rolling process [20]. Zhe-Long et al. [21] conducted research on the effect of warm surface rolling on the fatigue properties of H13 steel. They found that deep rolling conducted at certain elevated temperatures will further increase the fatigue resistance of $\mathrm{H} 13$ steel compared to deep rolling conducted at room temperature.

In this investigation, the surface-densified powder metallurgy parts were fabricated by using the warm rolling surface densification process. The influences of rolling temperature on the surface densification effect were investigated by analyzing the surface structure, surface density, and abrasion resistance of the warm rolling samples, and the mechanism of the strengthening effect in the warm rolling process is discussed.

\section{Materials and Methods}

\subsection{Preparation of Powder Metallurgy Parts}

The raw materials used in this study were the fully pre-alloyed powders purchased in Höganäs (Shanghai, China), which were pre-alloyed with $0.85 \%$ (mass ratio) Mo, $0.80 \%$ (mass ratio) $\mathrm{C}$, and $1.50 \%$ (mass ratio) $\mathrm{Cu}$, as shown in Table 1 . As an induction hardening process takes place after rolling, $0.8 \% \mathrm{C}$ is selected, which is high for rolling, but good for enhancing the hardness. Parts were manufactured on a mechanical press, with a forming pressure of $450 \mathrm{kN}$. The forming parts were then placed in a ceramic plate in a continuous mesh belt furnace under an ammonia atmosphere, and then sintered at $1130{ }^{\circ} \mathrm{C}$ for $30 \mathrm{~min}$. During the sintering process, the carbon potential in the furnace must be strictly controlled in order to ensure that the carbon content of the sintered parts remains at the initial level. The density of the sprocket parts after sintering is about $7.10 \mathrm{~g} / \mathrm{cm}^{3}$.

Table 1. Chemical composition of the PM (powder metallurgy) material.

\begin{tabular}{cccc}
\hline Element & $\mathbf{C}$ & $\mathbf{C u}$ & Astaloy 85Mo \\
\hline Content $(\%)$ & 0.80 & 1.50 & Balence \\
\hline
\end{tabular}

\subsection{Warm Rolling Densification}

The warm rolling densification process was carried out on a FLEX M20 HCN roller press developed by Escofier, Chalon-sur-Saône, France. The schematic diagram is shown in Figure 1. The samples were heated and preserved in a muffle furnace (Shanghai electrical furnace company, Shanghai, China) before the rolling process. The heating temperature was set as $100{ }^{\circ} \mathrm{C}, 200{ }^{\circ} \mathrm{C}, 300^{\circ} \mathrm{C}$, and the preserving time was $20 \mathrm{~min}$. After that, the parts were immediately transferred to the rolling 
machine to start the warm rolling process. The feed rate for the rolling was $0.6 \mathrm{~mm} / \mathrm{s}$, the mold turning speed was $30 \mathrm{r} / \mathrm{min}$, the roll feed was $0.8 \mathrm{~mm}$, and the pressure preserving time was $0.67 \mathrm{~s}$.

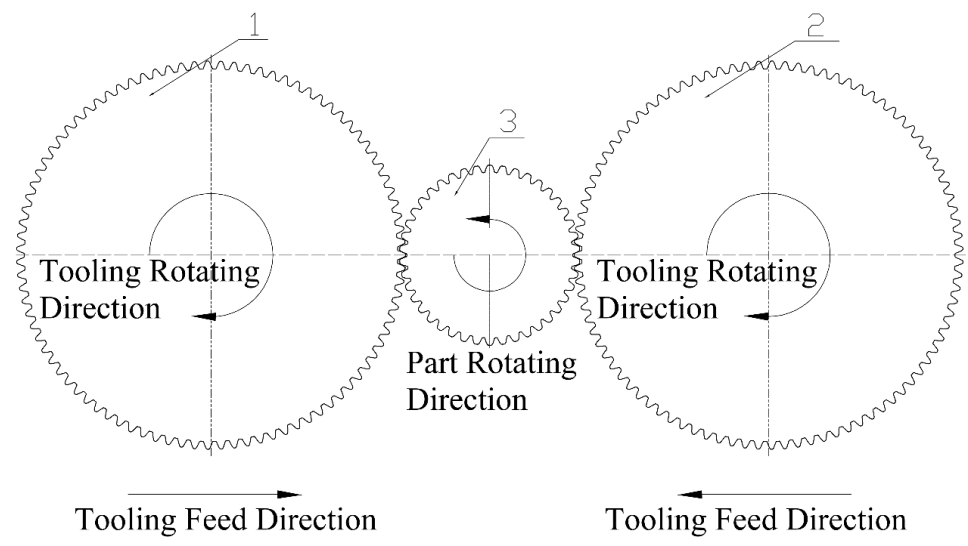

Figure 1. Schematic diagram of the densification of the rolling surface. 1 and 2: Rolling tool; 3: Sample.

\subsection{Characterization}

The microstructure of the dense layer in the PM parts was measured with a metallographic microscope (Olympus, BX51; Tokyo, Japan). The micro hardness was characterized with a Vickers hardness tester (DHV-1000; Shangguang, Shanghai, China) for 10 samples. The micro hardness was tested for each $0.1 \mathrm{~mm}$ from the surface to the core of the samples. The micro hardness distribution curves were obtained by collecting the hardness values, which were tested repeatedly for multiple samples. The wear resistance was investigated with a nano-scratch tester (CSM, NST, Peseux, Switzerland). The fracture morphology of the parts was studied with a scanning electron microscope (Apollo 300, CamScan, Cambridgeshire, UK).

\section{Results and Discussion}

\subsection{Surface Density Analysis}

The porosity was measured by using the binary image processing of the metallographic photos, in which an area ratio of pore judged black in the bitmap image of the observation area was calculated at an interval of $0.1 \mathrm{~mm}$ depth. Figure 2 shows the plot of the porosity distribution of the samples rolled under different rolling temperatures of $100{ }^{\circ} \mathrm{C}, 200{ }^{\circ} \mathrm{C}$, and $300^{\circ} \mathrm{C}$ as well as the cold-rolled sample. It can be seen that the surface porosity of the samples after warm rolling was lower than that after cold rolling. For iron-based materials, the density is $7.8 \mathrm{~g} / \mathrm{cm}^{3}$ at the fully-densified state, and it can be considered as a densified state when the porosity decreases below $3.84 \%$ and the density reaches $7.5 \mathrm{~g} / \mathrm{cm}^{3}$ [3]. Therefore, the depth of the densified layer can be calculated from the figures of the microstructure. The calculated results are shown in Table 2. It can be seen that the depth of the densified layer increased firstly and then decreased with the increase of rolling temperature, and the minimum densified depth of the sample was $0.61 \mathrm{~mm}$, which was prepared by cold rolling. When the rolling temperature was $200{ }^{\circ} \mathrm{C}$, the depth of the densified layer was $1.12 \mathrm{~mm}$. When the rolling temperature exceeded $200{ }^{\circ} \mathrm{C}$, the depth of surface densified layer decreased. This phenomenon was mainly resulted from the hydrostatic pressure during the rolling process and the plastic deformation resistance of the material, which will be further explained later. 


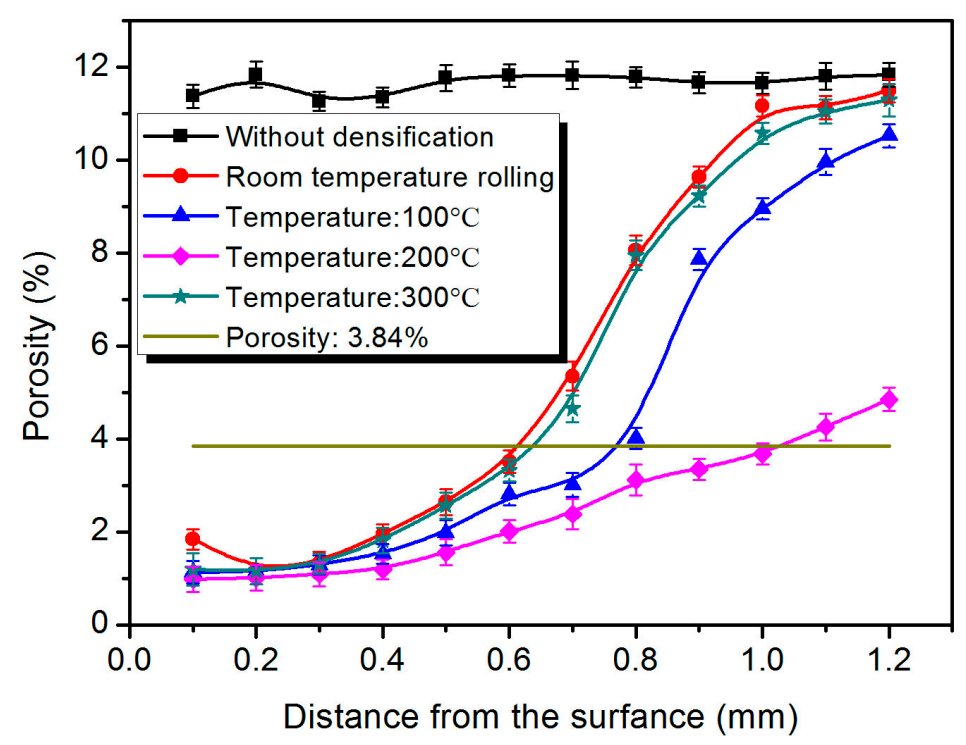

Figure 2. Different rolling temperatures and sample porosity distribution curves.

Table 2. Thickness of the surface densified layer of samples at different rolling temperatures (RT: Room temperature).

\begin{tabular}{ccccc}
\hline Temperature $\left({ }^{\circ} \mathrm{C}\right)$ & RT & $\mathbf{1 0 0}$ & $\mathbf{2 0 0}$ & $\mathbf{3 0 0}$ \\
\hline Depth of the densified layer $(\mathrm{mm})$ & 0.61 & 0.78 & 1.12 & 0.65 \\
\hline
\end{tabular}

Figure 3 shows the SEM images of the microstructure of different samples, including the pre-treated samples, cold-rolled samples, and samples rolled at different rolling temperatures. Figure 4 shows the images of the pores in different samples. From the figures, it can be seen that there was a large amount of pores in the unrolled PM parts, while the rolled samples has a relatively lower porosity on the edge. When the rolling proceeded, the particles in the surface layer moved under the axial pressure [22]. The particles kept moving, rotating, and rubbing, and the particles were compressed and deformed. The deformation and slippage of the particles caused the compressive deformation of the pores between the particles, and eventually the pores became smaller or even disappeared. At the beginning of the deformation, the particles near the pores were pressed against each other under pressure, and the pores were flattened into oval shapes. With the increase of the amount of deformation, the particles flowed and the pores suffered with the shear stress as well as the hydrostatic pressure, which further compressed the pores. Under the existence of shear stress, the pores were elongated and dispersed into small holes, or even completely bonded together to form a metallurgical combination, and the gap finally disappeared [23]. Whether cold rolling or warm rolling was employed, the samples suffer the external force due to plastic deformation, and the density of the samples increases as a result.

As is shown in Figure 3, the samples rolled at a certain temperature had a lower porosity. When the pre-heating temperature was $200{ }^{\circ} \mathrm{C}$, the sample reached the deepest densified layer. During the rolling process, the sample suffered the superposition of hydrostatic pressure and shear stress. The hydrostatic pressure promotes the volume reduction of the pores, and the shear stress causes the plastic deformation of the material. The greater the hydrostatic pressure is, the greater the compressive stress of plastic deformation will be. When the sample was heated, the plasticity of the sample would be improved. Therefore, during the warm rolling process, the hydrostatic pressure acting on the samples and the plastic deformation resistance of the material determined the shrinkage deformation of the pores. That is, the higher the pre-heated temperature is, the smaller the plastic deformation resistance of the material is, and the smaller the hydrostatic pressure will be. 


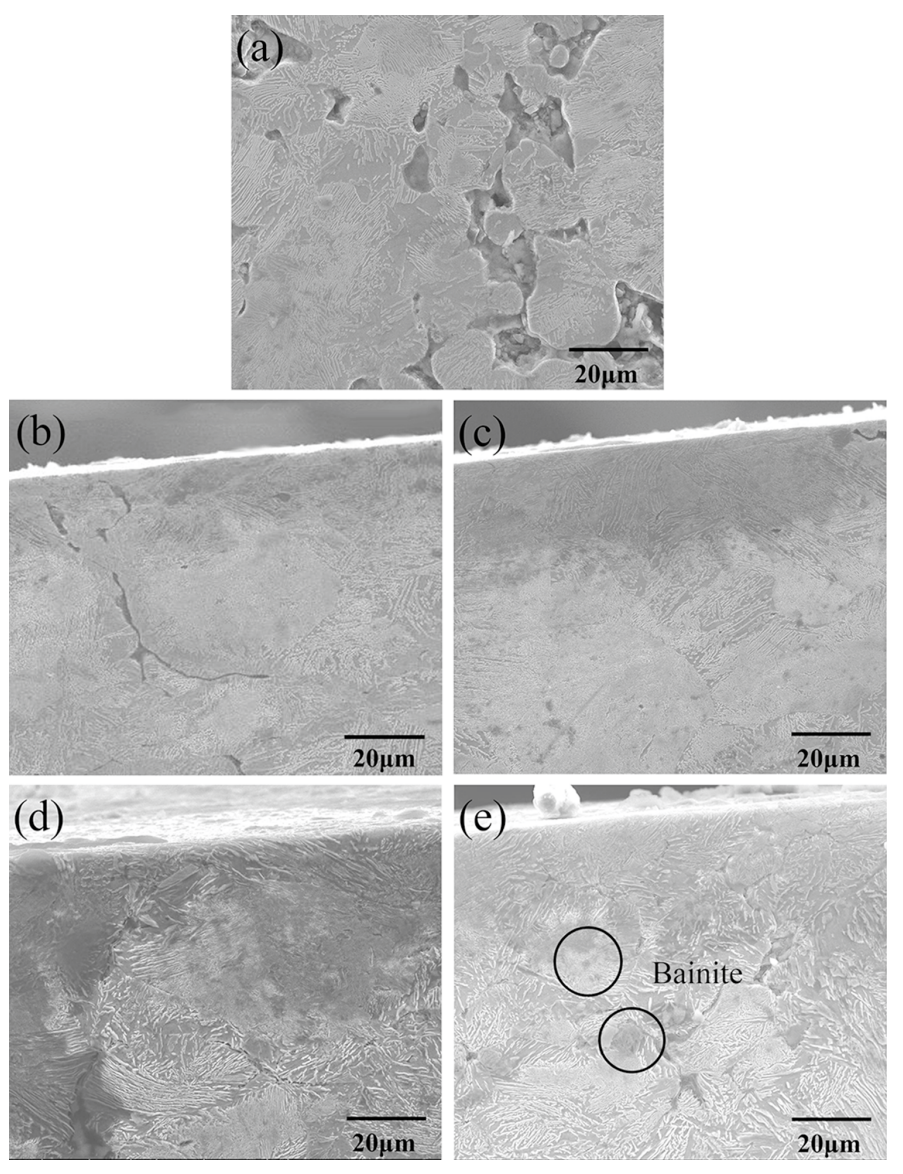

Figure 3. Microstructure images of different samples (a) unrolled (b) cold-rolled; (c) rolled with a pre-heated heating temperature of $100{ }^{\circ} \mathrm{C}$; (d) rolled with a pre-heated heating temperature of $200{ }^{\circ} \mathrm{C}$; (e) rolled with a pre-heated heating temperature of $300^{\circ} \mathrm{C}$.

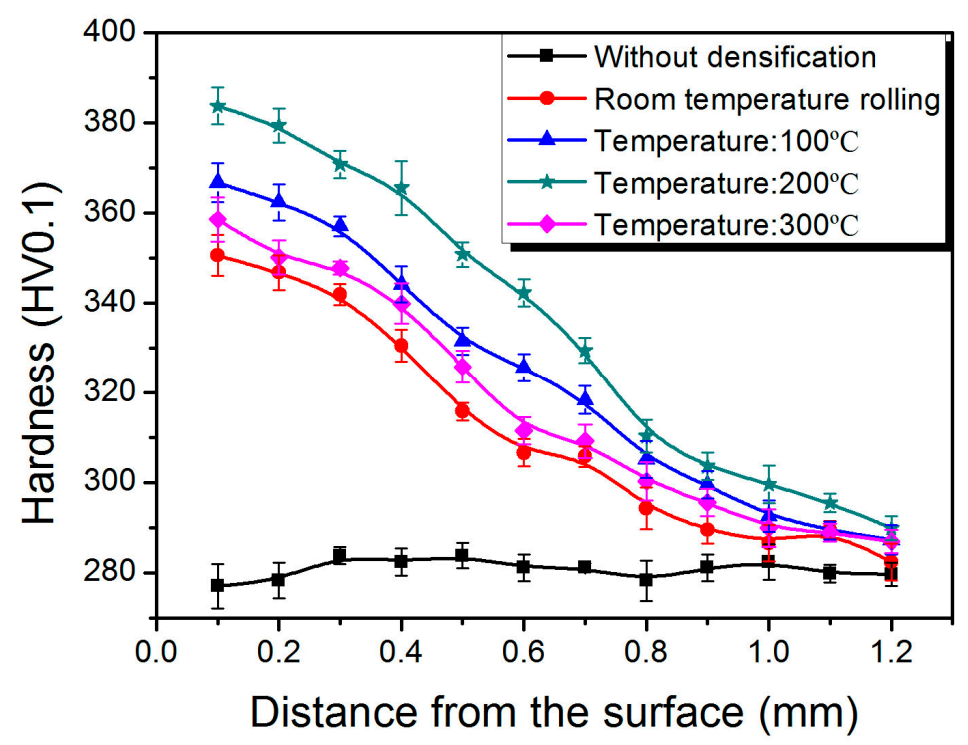

Figure 4. Distribution curves of the micro hardness of different rolled samples at different temperatures.

An optimum temperature is needed in order to obtain the best surface densification. In this study, the rolling pressures of the samples with different rolling temperatures are shown in Table 3. As can be seen from Table 3, the rolling pressure first decreased and then increased with the increasing 
rolling temperature. When the pre-heated temperature was $200^{\circ} \mathrm{C}$, the rolling pressure reached the smallest value. The hydrostatic pressure of the cold-rolled sample was the largest, but also the plastic deformation resistance was the largest. When the sample was heated to $100^{\circ} \mathrm{C}$, the hydrostatic pressure of the sample was reduced and the shrinkage of the pores was reduced. The plastic deformation resistance was also reduced, and the pores welding effect was enhanced. In this case, the enhancement effect of the pore welding was greater than that of the pore shrinkage, which led to the improvement of the surface densification of the sample. When the sample was heated to $200{ }^{\circ} \mathrm{C}$, the plastic deformation resistance of the material was further reduced and the pore welding was further enhanced. At the same time, the reinforcement effect of the pore was still larger than that of the pore shrinkage, which still led to the improvement of the surface densification of the sample. However, when the pre-heated temperature reached $300{ }^{\circ} \mathrm{C}$, the sample cooled down faster and bainite was produced in the material due to larger temperature difference between the sample and the external during the rolling process, as shown in Figure 3e. The hardness of the material increased with the production of bainite, and the rolling pressure was increased along with the plastic deformation resistance. Therefore, the pore welding capacity of the sample was reduced. The increase of pressure was favorable for the shrinkage of pores, but the weakening effect of pore welding was greater than that of pore shrinkage. Therefore, when the pre-heated temperature was $300^{\circ} \mathrm{C}$, the degree of surface densification was reduced.

Table 3. Rolling force values at different rolling temperatures.

\begin{tabular}{ccccc}
\hline Temperature $\left({ }^{\circ} \mathbf{C}\right)$ & RT & $\mathbf{1 0 0}$ & $\mathbf{2 0 0}$ & $\mathbf{3 0 0}$ \\
\hline Rolling pressure $(\mathrm{kN})$ & 45.40 & 42.83 & 40.29 & 45.47 \\
\hline
\end{tabular}

\subsection{Microscopic Hardness Analysis}

In order to investigate the mechanical properties of the samples rolled at different temperatures, the micro hardness measurements of different samples were carried out. In the measurements, several points along the direction normal to the surface were taken to conduct the micro hardness tests; these tests were repeated several times and the statistical micro hardness was plotted and shown in Figure 4. It can be seen from the figure that the hardness of the products that have not been rolled were not changed from the surface to the core part. However, after the rolling process, the hardness of the surface of the parts was improved, while the core region of the parts was barely changed. The parts pre-heated at $200{ }^{\circ} \mathrm{C}$ had the highest surface hardness. When the pre-heated temperature reached $30{ }^{\circ} \mathrm{C}$, the surface hardness of parts decreased. The hardness is related to the densification state of the parts. Since the samples pre-heated to $200{ }^{\circ} \mathrm{C}$ had the highest density, those samples also had the highest surface hardness.

\subsection{Wear Resistance Analysis}

The nano-scratch tests were analyzed to investigate the wear resistance properties of the samples prepared at different rolling temperatures. The curves of the penetration depth and length are shown in Figure 5. As shown in the figure, the depth curve of nano-scratches in the sample rolled at $200{ }^{\circ} \mathrm{C}$ decreased with the increase of scratch scale, while the depth curve of the samples rolled at other temperatures fluctuated greatly. This result indicates that the sample pre-heated at $200{ }^{\circ} \mathrm{C}$ has the lowest porosity and the best densification state. As shown in Table 4, it was found that with the increase of the rolling temperature, the depth of the scratch of the sample decreased first and then increased. The sample pre-heated to $200{ }^{\circ} \mathrm{C}$ had an average depth of $0.29 \mu \mathrm{m}$, which indicates the highest hardness among the samples. 


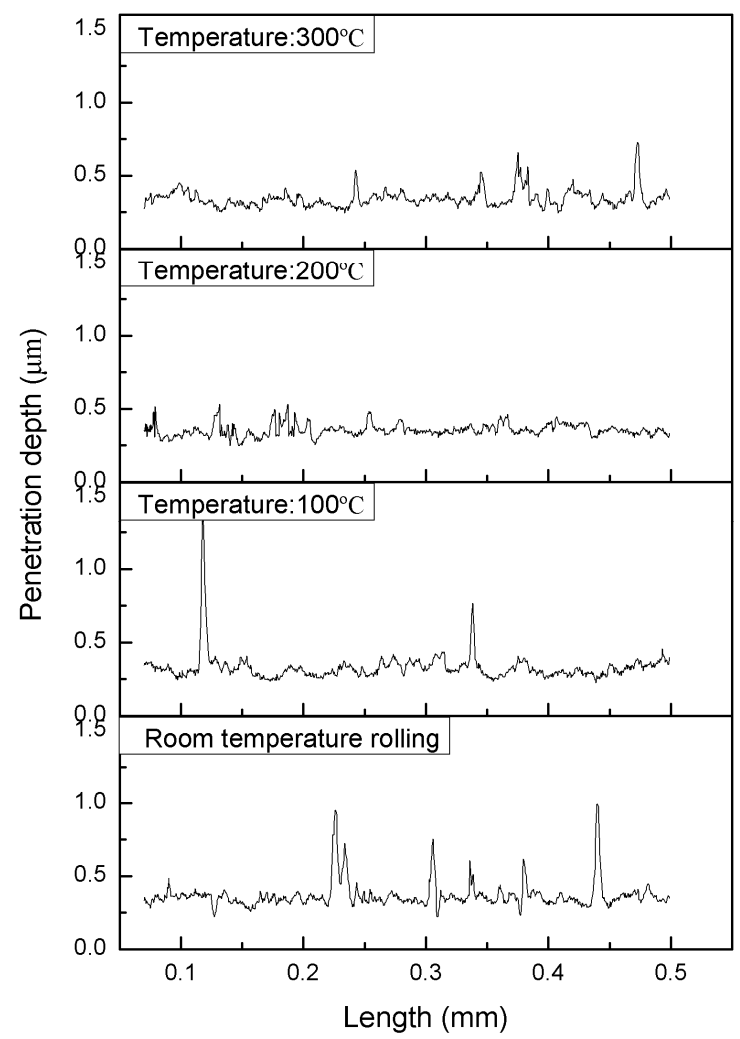

Figure 5. Distribution curves of the depth of nanometer scratches of the length of the slit.

Table 4. Average depth of nanometer scratches for the preparation of dense areas of samples at different temperatures.

\begin{tabular}{lllll}
\hline Temperature $\left({ }^{\circ} \mathbf{C}\right)$ & $\mathbf{R T}$ & $\mathbf{1 0 0}$ & $\mathbf{2 0 0}$ & $\mathbf{3 0 0}$ \\
\hline Strach depth $(\mu \mathrm{m})$ & 0.3 & 0.30 & 0.29 & 0.32 \\
\hline
\end{tabular}

Figure 6 shows the friction coefficient of the compact zone of the samples with different pre-heated temperatures. The friction coefficient was measured by a nano-scratch tester. Nano-scratch tests were set at a fixed carrier mode, and the scoring load was $10 \mathrm{mN}$. The curvature radius of the diamond ball tip was $2 \mu \mathrm{m}$, and the scribing speed was $0.6 \mathrm{~mm} / \mathrm{min}$. The friction coefficient can be obtained by moving the diamond ball tip on the samples. It can be seen from Figure 6 that when the pre-heated temperature was $200{ }^{\circ} \mathrm{C}$, the friction coefficient of the prepared sample was the smallest. In the above study, it has been proven that the samples pre-heated at $200{ }^{\circ} \mathrm{C}$ had the optimal hardness. The wear resistance is closely related to the hardness and friction coefficient, so that the higher the hardness was, the smaller the friction coefficient was, and the better the wear resistance of the material would be. Therefore, when the pre-heated temperature is $200^{\circ} \mathrm{C}$, the prepared samples had the best abrasion resistance.

We also conducted research on the gear tooth profile changing process by FEA (Finite elemental analysis) simulation and experiments. Before rolling, the tooth profile was designed with a small margin. During the rolling process, the tooth profile gradually align with the true involute. The detailed investigation of the FEA simulation will be introduced in a future paper. 


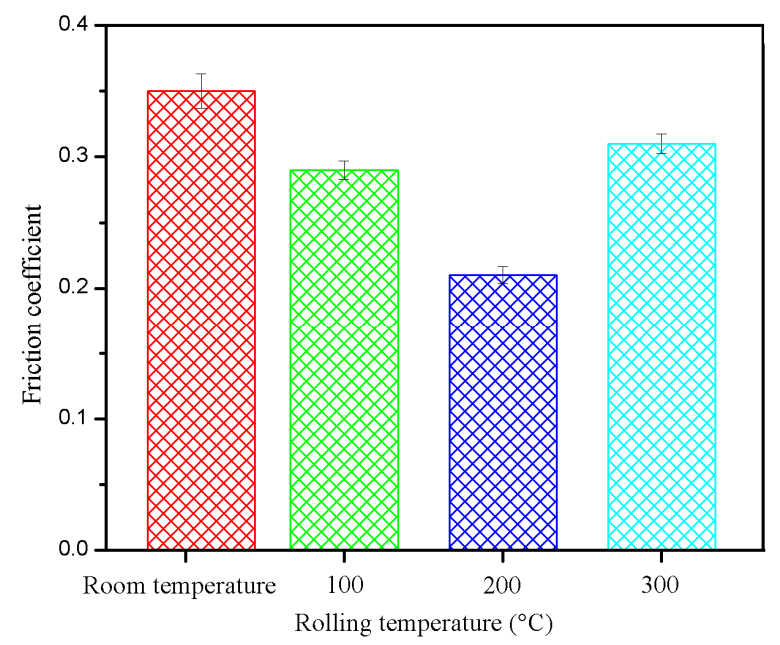

Figure 6. Friction coefficient of the densified area of the samples prepared with different pre-heated temperatures.

\section{Conclusions}

In this study, the effect of different rolling temperatures on the microstructure and mechanical properties of powder metallurgy Fe-based gears prepared by the surface rolling densification process was investigated in details. It was found that the sample prepared with a pre-heated temperature of $200{ }^{\circ} \mathrm{C}$ had the lowest porosity at the edge of the sample port. Also, for the sample rolled at a pre-heated temperature of $200{ }^{\circ} \mathrm{C}$, the surface hardness value was the highest, and so was the wear resistance. The hydrostatic pressure acting on the sample and the plastic deformation resistance of the sample itself determine the surface densification behavior. With the increase of the temperature during the rolling process, the resistance of the sample to plastic deformation decreases. When the pre-heated temperature reaches $300{ }^{\circ} \mathrm{C}$, due to the rapid cooling of the sample, bainite is generated and the hardness of the material increases, which results in the inferior densification effect of the samples pre-heated at $300{ }^{\circ} \mathrm{C}$.

Acknowledgments: This study was funded by the "Morning Star" project supported by the Science and Technological Commission of Shanghai, China.

Author Contributions: Wei Lu and Jingguang Peng conceived and designed the experiments; Biao Yan, Jingguang Peng, Di Chen and Dekai Li performed the experiments; Dekai Li and Taolei Wang analyzed the data; Taolei Wang and Jingguang Peng wrote the paper; Wei Lu revised the manuscript. All authors discussed and approved the final manuscript.

Conflicts of Interest: The authors declare no conflict of interest.

\section{References}

1. Takemasu, T.; Koide, T.; Takeda, Y.; Kamimura, D.; Nakamoto, M. Properties of densification by surface rolling and load bearing capacity of $1.5 \mathrm{Cr}-0.2 \mathrm{Mo} \mathrm{high}$ density sintered steel rollers and gears. J. Solid Mech. Mater. Eng. 2011, 5, 825-837. [CrossRef]

2. Klocke, F.; Schröder, T.; Kauffmann, P. Fundamental study of surface densification of PM gears by rolling using FE analysis. Prod. Eng. 2007, 1, 113-120. [CrossRef]

3. Peng, J.; Zhao, Y.; Chen, D.; Li, K.; Lu, W.; Yan, B. Effect of surface densification on the microstructure and mechanical properties of powder metallurgical gears by using a surface rolling process. Materials 2016, 9, 846 . [CrossRef] [PubMed]

4. Luo, X.; Liu, Y.; Gu, C.; Li, Z. Study on the progress of solidification, deformation and densification during semi-solid powder rolling. Powder Technol. 2014, 261, 161-169. [CrossRef]

5. Kang, D.H.; Hong, J.K.; Park, N.K.; Kim, T.W. Densification behavior of titanium in direct powder rolling process. Trans. Korean Soc. Mech. Eng. A 2012, 36, 1255-1260. [CrossRef] 
6. He, J.; Zhao, A.; Huang, Y.; Zhi, C.; Zhao, F. Acceleration of bainite transformation at low temperature by warm rolling process. Mater. Today Proc. 2015, 2, 289-294. [CrossRef]

7. Storojeva, L.; Ponge, D.; Kaspar, R.; Raabe, D. Development of microstructure and texture of medium carbon steel during heavy warm deformation. Acta Mater. 2004, 52, 2209-2220. [CrossRef]

8. Datsko, J.; Hartwig, L.; Mcclory, B. On the tensile strength and hardness relation for metals. J. Mater. Eng. Perform. 2001, 10, 718-722. [CrossRef]

9. Zhao, Z.; Liu, C.; Northwood, D.O. The warm deformation treatments for improving the resistance of high strength steel wires to low cycle fatigue and room temperature creep. Rare Met. Mater. Eng. 1999, 28, 569-573.

10. Gunter, R.; Lorenz, S.S. PM Gear for a Passenger Car Gear Box. In Proceedings of the International Conference on Gears, Munich, Germany, 14-16 September 2005.

11. Lorenz, S.S.; Gunter, R.; Delarbre, P. Quantification of Selective Surface Densification in PM Components. In Proceedings of the International Conference on Powder Metallurgy and Particulate Materials, Montreal, QC, Canada, 19-23 June 2005.

12. Takemasu, T.; Koide, T.; Shinbutsu, T.; Sasaki, H.; Takeda, Y.; Nishida, S. Effect of surface rolling on load bearing capacity of pre-alloyed sintered steel gears with different densities. Procedia Eng. 2014, 81, 334-339. [CrossRef]

13. Sasaki, H.; Shinbutsu, T.; Amano, S.; Takemasu, T.; Sugimoto, S.; Koide, T.; Nishida, S. Three-dimensional complex tooth profile generated by surface rolling of sintered steel helical gears using special CNC form rolling machine. Procedia Eng. 2014, 81, 316-321. [CrossRef]

14. Jones, P.K.; Buckley-Golder, K.; Lawcock, R. Densification strategies for high endurance P/M components. Int. J. Powder Metall. 1997, 33, 37-44.

15. Koide, T.; Ishizuka, I.; Takemasu, T.; Miyachika, K.; Fukai, Y. GSD-02 Load Bearing Capacity of Surface-Rolled High Density Sintered Metal Gears (Gear Strength and Durability, Including Gear Materials and Heat Treatment Techniques). In Proceedings of the JSME International Conference on Motion and Power Transmissions, Kyoto, Japan, 1-3 March 2017; The Japan Society of Mechanical Engineers: Kyoto, Japan, 2017; pp. 313-316.

16. Jandeska, W.; Hoffmann, G.; Slattery, R. Rolling contact fatigue of surface densified FLN2-4405. Int. J. Powder Metall. 2005, 41, 49-56.

17. Liu, X.; Xiao, Z.; Guan, H.; Zhang, W.; Li, F. Friction and wear behaviours of surface densified powder metallurgy Fe-2Cu-0.6C material. Powder Metall. 2016, 59, 329-334. [CrossRef]

18. Bhargava, S.; Dube, R.K. Changes in the longitudinal flow and apparent plastic Poisson's ratio of a porous metal strip during hot densification rolling. Metall. Trans. A 1988, 19, 1205-1211. [CrossRef]

19. Ehinger, D.; Krüger, L.; Martin, U.; Weigelt, C. Temperature effects on the deformation behavior of high-density trip steel and particle-reinforced TRIP steel/zirconia honeycombs under quasi-static compressive loading. Adv. Eng. Mater. 2013, 15, 646-657. [CrossRef]

20. Richards, M.D.; Burnett, M.E.; Speer, J.G.; Matlock, D.K. Effects of deformation behavior and processing temperature on the fatigue performance of deep-rolled medium carbon bar steels. Metall. Mater. Trans. A 2013, 44, 270-285. [CrossRef]

21. Zhe-Long, H.E.; Lei, L.P.; Pan, Z. Effect of warm surface rolling on fatigue property of H13 steel. J. Plast. Eng. 2017, 24, 74-78.

22. Lee, C.S.; Duggan, B.J.; Smallman, R.E. A Theory of deformation banding in cold rolling. Acta Metall. Mater. 1993, 41, 2265-2270. [CrossRef]

23. Sigl, L.S.; Rau, G.; Dennert, C. Selective surface densification for high performance P/M components. Powder Metall. Technol. 2012, 30, 144-150.

(C) 2017 by the authors. Licensee MDPI, Basel, Switzerland. This article is an open access article distributed under the terms and conditions of the Creative Commons Attribution (CC BY) license (http:/ / creativecommons.org/licenses/by/4.0/). 